\title{
Epstein-Barr Virus Induces Aggressive Lymphoproliferative Disorders of Human B Cell Origin in SCID/hu Chimeric Mice
}

\author{
M. J. Cannon, P. Pisa, R. I. Fox, and N. R. Cooper \\ Research Institute of Scripps Clinic, Department of Immunology, La Jolla, California 92037
}

\begin{abstract}
C.B-17 scid mice were reconstituted by intraperitoneal injection of human tonsil cells or PBL from EBV-seronegative donors. Subsequent injection of EBV resulted in the rapid development (within 19-33 d) of aggressive, fatal, lymphoproliferative disorders of human B cell origin. Autopsies revealed solid tumors in the abdomen, and occasionally in the liver, thymus, or spleen. Histopathologic analysis showed that the tumors were high-grade immunoblastic lymphomas and FACS analyses of tumor cells indicated that they were of human Blymphoid origin. The tumor cells grew in vitro and induced new tumors on injection into severe combined immunodeficient (SCID) mice. Karyotypic analysis and Southern blots for c-myc or bcl-2 rearrangements revealed no chromosomal abnormalities and translocations. Southern blot analysis also showed that the cells possessed EBV DNA sequences. Although these tumors undoubtedly reflect infection of the transferred $B$ cells with $E B V$ in vivo, intraperitoneal transfer of short-term lymphoid cell lines transformed in vitro with EBV resulted in ascites production without evidence of tumor formation. (J. Clin. Invest. 1990. 85:1333-1337.) Epstein-Barr virus $\bullet B$ cells $\bullet$ lymphoma $\bullet$ SCID mice

\section{Introduction}

Epstein-Barr virus (EBV), a human herpesvirus, is strongly associated with two human malignancies, Burkitt's lymphoma and nasopharyngeal carcinoma. EBV has also been implicated in the B cell lymphomas and lymphoproliferative disorders that occur in immunosuppressed recipients of organ allografts (1-3), and in AIDS patients with disease-associated immunosuppression $(4,5)$. While the EBV genome is generally present in the proliferating cells in these conditions, there is limited information on its role in pathogenesis, since the natural host range is limited to man. Although new world monkeys, particularly cotton-top tamarins, develop tumors and lymphoproliferative disease 14-21 d after EBV injection (6-8), these animals are endangered and not generally available. In this paper

Address reprint requests to Dr. Cannon, Research Institute of Scripps Clinic, Department of Immunology, 10666 North Torrey Pines Road, La Jolla, CA 92037.

Received for publication 20 October 1989 and in revised form 28 December 1989.

J. Clin. Invest.

(C) The American Society for Clinical Investigation, Inc.

$0021-9738 / 90 / 04 / 1333 / 05 \$ 2.00$

Volume 85, April 1990, 1333-1337 we describe a novel model for EBV-induced human lymphoproliferative disease. We report that EBV infection of mice with severe combined immunodeficiency (SCID) ${ }^{1}(9)$ reconstituted by intraperitoneal injection of PBL from EBV seronegative donors (or tonsil cells) is followed 19-33 $d$ later by the development of aggressive fatal lymphoproliferative disorders of human B cell origin. The tumors contain EBV and are histologically similar to human EBV-positive posttransplant lymphomas. Unlike the recently reported spontaneous development of human B cell lymphoblastic lymphomas in SCID mice 2- 4 mo after reconstitution with PBL from EBV seropositive but not seronegative donors (10), the contributions of EBV, the target $B$ cell and $T$ cell immunity can be rapidly and independently assessed in this new model. In common with another recent description of SCID/hu chimeras (10), we found no evidence of graft-versus-host disease; the reasons for this unexpected xenospecific anergy are currently unknown.

\section{Methods}

Epstein-Barr virus. Supernatants of PMA-treated B95-8 cell cultures were used directly or concentrated by centrifugation at $60,000 \mathrm{~g}$ for 90 $\min$. All virus preparations were frozen in liquid $\mathrm{N}_{2}$ before use.

Human lymphocytes. PBL from venous blood or tonsil cells from therapeutic tonsillectomies were obtained by Ficoll-Hypaque separation. The EBV immune status of blood donors was assessed with a commercial assay for serum antibody against EBV capsid antigen (Electro-Nucleonics, Inc., Columbia, MD).

Mice. C.B-17 scid (SCID) mice (9), aged 8-12 w, were from the Research Institute of Scripps Clinic breeding colony, which is free of mouse hepatitis virus. SCID mice were reconstituted by intraperitoneal injection of at least $5 \times 10^{7}$ human PBL or tonsil cells; such mice are hereafter referred to as SCID/hu chimeras.

Recovery of tumor cells; in vitro culture. Cells were recovered from solid tumors by treatment of minced tissue with collagenase and trypsin, after a previously described method (11). Tumor cells were cultured in RPMI 1640 supplemented with antibiotics, glutamine, and $10 \%$ FCS (Hyclone, Logan, UT).

Lymphoid cell lines $(L C L)$. EBV-transformed LCL were prepared by infection of PBL with B95-8 virus in the presence of Cyclosporin A (Sandoz, East Hanover, NJ), as previously described (12).

Antibodies. The following monoclonal antibodies were used for flow cytometric (FACS) analysis of tumor cells: anti-CD20 (Coulter, Hialeah, FL); RR1/1 (anti-LFA-3) and TS2/9.1 (anti-ICAM-1), kindly provided by Dr. T. A. Springer (Harvard Medical School); OKT3 (anti-CD3), HB5 (anti-CD21), 3D9 (anti-CD35), and M1/42 (against a species-specific common determinant on mouse MHC class I molecules) from the American Type Culture Collection (Rockville, MD).

1. Abbreviations used in this paper: LCL, lymphoblastoid cell line; SCID, severe combined immune deficient (mice). 
FITC-F(ab') ${ }_{2}$ goat anti-human IgG and IgM (H \& L) were from Accurate Corp. (New York). Goat anti-human kappa or lambda light chain was from Organon Teknika, West Chester, PA. A FACS IV analyzer (Becton-Dickinson Co., Rutherford, NJ) was used for flow cytometry.

Histopathology. Tissue samples were fixed in B-5 formalin (6\% $\mathrm{HgCl}_{2}, 12.5 \% \mathrm{CH}_{3} \mathrm{COONa}, 4 \%$ formaldehyde), and sections stained (hematoxylin/eosin) or subjected to immunohistochemical analyses with antibodies specific for human B cells.

Southern blot assays. Tumor cell DNA was analyzed by Southern blots as described (13), using specific ${ }^{32} \mathrm{P}$-labeled DNA probes. $20 \mu \mathrm{g}$ of tumor cell genomic DNA was digested with Eco RI or Msp I, electrophoresed in $0.7 \%$ or $1.7 \%$ agarose gels, respectively, and transferred by the alkaline blot method to nylon membranes, which were hybridized with the DNA probes. EBV DNA was detected with an Msp I fragment of the B95-8 Bam HI K region (coding for EBNA-1), from a pBR322EBV recombinant library (14). Probes for c-myc and bcl-2 oncogenes were from Oncor, Gaithersburg, MD.

\section{Results}

EBV infection of SCID/hu chimeras. PBL from four EBV-seronegative donors (designated J. R., D. P., N. H., and T. C.) and tonsil cells from one donor of unknown EBV status (age 4 yr) were transferred intraperitoneally to SCID mice. The mice were injected 7-16 d later with a 40-fold concentrate of B95-8 supernatant (usually $150 \mu \mathrm{l}$ i.p. and/or $150 \mu$ li.v.), except for the recipients of 4-yr-old tonsil cells, which received $1 \mathrm{ml}$ of B95-8 supernatant $(0.8 \mathrm{ml}$ i.p., $0.2 \mathrm{ml}$ i.v.). These experiments are summarized in Table I.

All $10 \mathrm{SCID} / \mathrm{hu}$ chimeric recipients of intraperitoneally injected EBV (with or without concomitant intravenous EBV injection) developed clinical signs of disease 19-33 d later. Autopsies revealed that all EBV-infected chimeras had abdominal solid tumors (3-15 mm diam), often closely associated with the liver; additional tumors were found in the thymus or spleen of some mice. No signs of disease were observed up to day 67 after intravenous injection of EBV (Table I), indicating that the intraperitoneal route of EBV injection is primarily responsible for lymphoproliferative disease. Uninfected
SCID/hu chimeras have shown no clinical signs of disease up to $109 \mathrm{~d}$ postreconstitution with human cells.

Histopathologic characterization of tumors. Examination of stained sections indicated that tumors were high-grade large B cell immunoblastic lymphomas with conspicuous plasmacytoid cytologic atypia and well-defined areas of necrosis (Fig. $1 A$ ). They were thus similar to human EBV-positive posttransplant lymphoproliferative disorders. Immunohistochemical analyses indicated that the tumor cells were of human B cell origin (not shown).

FACS analysis. In every experiment, viable cells were recovered from the tumors and cell lines established. Phenotypic analysis by flow cytometry confirmed that the cells were of B lymphoid origin; cells were positive for CD20, CD21, and for human Ig expression (not shown). Where examined, tumor cells expressed low levels of both kappa and lambda Ig light chains, indicating that the tumor cells were oligoclonal or polyclonal. High levels of ICAM-1 and LFA-3 expression, typical of EBV-transformed LCL (15), were also observed (not shown). Tumor cells were negative for human CD3 and mouse class I MHC molecules. FACS analysis also excluded the possibility of inadvertent transfer of live B95-8 cells to the SCID mice: tumor cells (and LCL) were positive for CD35 and ICAM-1, whereas MAb for these markers failed to stain B95-8 cells.

Genetic analysis. Preliminary karyotype analysis of cells from one of the tumors (by Dr. O. W. Jones, University of California, San Diego) showed them to be normal diploid cells without chromosomal abnormalities. The number of metaphase spreads analyzed would have detected abnormalities in $25 \%$ or greater of the cells. Supporting this observation, Southern blot assays on D. P. and J. R. SCID/hu chimera tumor cells revealed no evidence of c-myc or $b c l-2$ rearrangements (not shown). Southern blots also showed that tumor cells possessed B95-8 EBV Bam HI K (EBNA-1 coding region) DNA sequences.

Adoptive transfer of the tumors. Cells were recovered from a SCID/hu (donor J. R. PBL) tumor, cultured and expanded

Table I. EBV Infection of SCID/hu Chimeras

\begin{tabular}{|c|c|c|c|c|}
\hline \multirow[b]{2}{*}{ Cells transferred $\left(5 \times 10^{7}\right.$, i.p. $)$} & \multirow{2}{*}{$\begin{array}{l}\text { No. of } \\
\text { mice }\end{array}$} & \multicolumn{2}{|c|}{ EBV Infection } & \multirow[b]{2}{*}{ Gross pathology } \\
\hline & & Time & Route & \\
\hline Donor D.P. PBL & 2 & Day 10 & i.p., i.v. & $\begin{array}{l}2 / 2 \text { clinically ill } 28-31 \mathrm{~d} \text { after EBV infection. } \\
\text { Tumors in abdomen, spleen, thymus }(2 / 2) \text {. }\end{array}$ \\
\hline Donor J.R. PBL & 2 & Day 7 & i.p., i.v. & $\begin{array}{l}2 / 2 \text { clinically ill } 19-20 \mathrm{~d} \text { after EBV infection. } \\
\text { Tumors in abdomen }(2 / 2) \text {. }\end{array}$ \\
\hline Donor N.H. PBL & 3 & Day 7 & i.p., i.v. & $\begin{array}{l}3 / 3 \text { clinically ill (one found dead) } 20-21 \mathrm{~d} \text { after EBV infection. } \\
\text { Tumors in abdomen }(3 / 3) \text {, thymus }(1 / 3) \text {. }\end{array}$ \\
\hline Donor T.C. PBL & 3 & Day 16 & i.p. & $\begin{array}{l}3 / 3 \text { clinically ill } 24-30 \mathrm{~d} \text { after EBV infection. } \\
\text { Tumors in abdomen/liver, thymus }(3 / 3) \text {. }\end{array}$ \\
\hline Donor T.C. PBL & 3 & Day 16 & i.v. & $\begin{array}{l}1 / 3 \text { no clinical signs up to day } 67 \text {. } \\
2 / 3 \text { ill days } 43-45 ; 2 \text { sacrificed; no tumors. }\end{array}$ \\
\hline Tonsil cells (4-yr-old donor) & 4 & Day 16 & i.p., i.v. & $\begin{array}{l}4 / 4 \text { clinically ill (one found dead) } 25-33 \mathrm{~d} \text { after EBV infection. } \\
\text { Tumors in abdomen (4/4). }\end{array}$ \\
\hline \multicolumn{5}{|c|}{ Adoptive transfer of SCID/hu tumor cells } \\
\hline $\begin{array}{l}\text { Donor J.R. SCID/hu tumor } \\
\text { cells } 4 \text { th pass in vitro }\end{array}$ & 3 & - & - & $\begin{array}{l}3 / 3 \text { clinically ill } 13-15 \mathrm{~d} \text { posttransfer } \\
\text { Tumors in abdomen }(3 / 3) \text {. }\end{array}$ \\
\hline
\end{tabular}



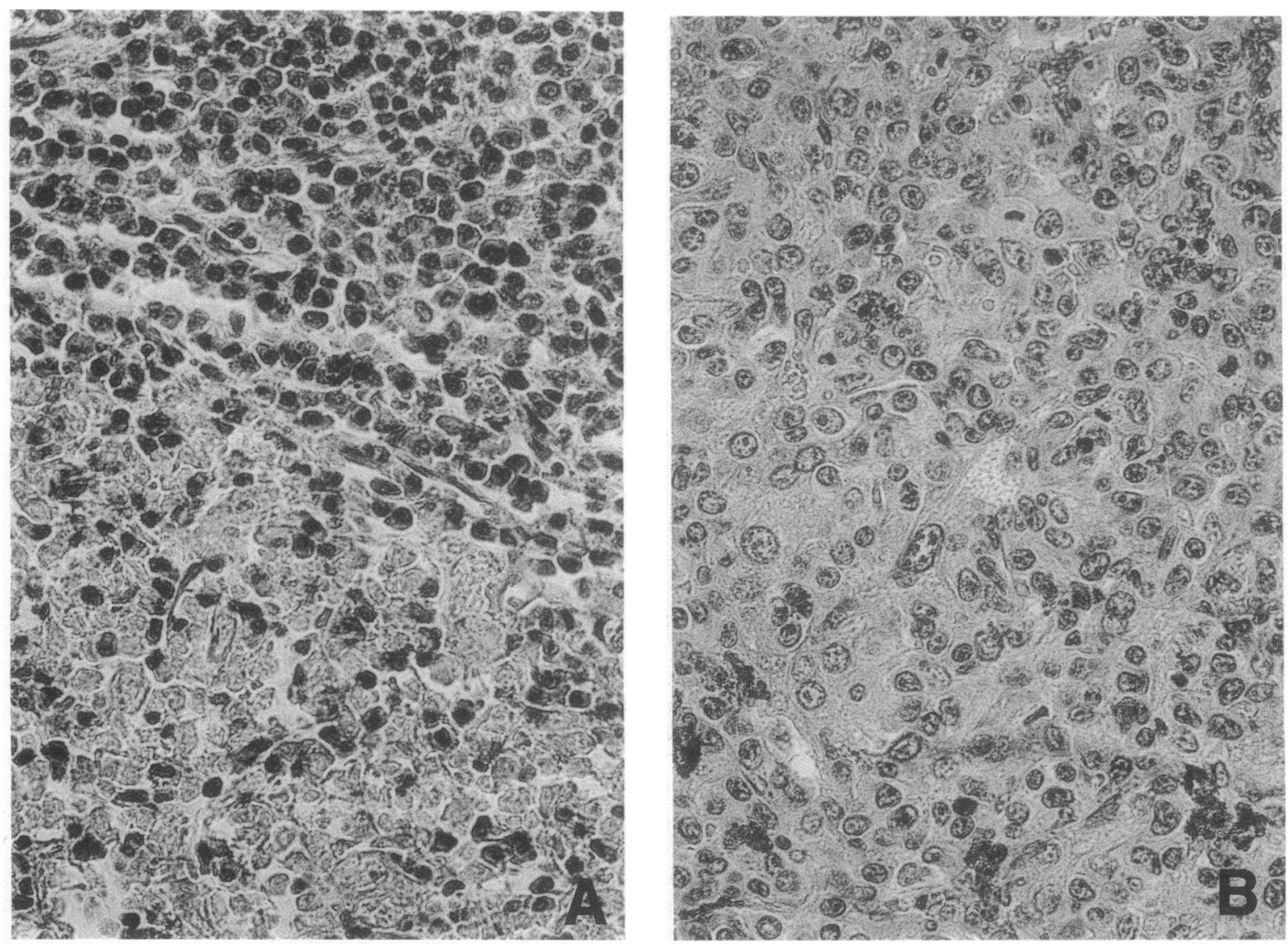

Figure 1. Histologic characteristics of SCID/hu tumors. $(A)$ Abdominal tumor appearing after EBV injection into SCID mice reconstituted with human tonsil cells. Plasmacytoid immunoblasts and a well-defined eosinophilic zone of necrosis (lower field) are evident. $(B)$ Less differentiated nonplasmacytoid tumor following transfer of long-term RS. LCL into SCID mice. Hematoxylin/eosin stain, $\times 40$.

through four weekly passages in vitro and transferred intraperitoneally to three SCID mice $\left(5 \times 10^{6}\right.$ cells/mouse $)$. All three mice became severely ill $13-15 \mathrm{~d}$ posttransfer, and autopsy demonstrated that all three had abdominal tumors. Viable cells were recovered, and shown by FACS analysis to be human B lymphoid cells. It was thus possible to reproduce disease and tumor induction by cell transfer, even after several cell passages in vitro.

Transfer of EBV-transformed LCL to SCID mice. Since the tumors described above were undoubtedly a direct result of EBV infection of B cells in vivo, it was considered important to determine whether LCL derived by in vitro infection and transformation with EBV could also produce tumors in SCID mice. LCL established from three individuals were used in transfer experiments, a synopsis of which is provided in Table II. Two of the LCLs, designated J. R. and D. P., respectively, were autologous to PBL used for SCID/hu chimeras. Although intraperitoneal EBV injection of the J. R. or D. P. SCID/hu PBL chimeras resulted in solid tumor formation, as described above, intraperitoneal transfer of $5 \times 10^{6} \mathrm{~J}$. R. or D. P. LCL to SCID mice induced ascites production 14-21 d later. Autopsies did not reveal any other gross pathology and there was no evidence of tumor formation. Only 1-2 $\mathrm{ml}$ of ascites fluid could be aspirated from the peritoneal cavity, but $>1 \times 10^{8}$ cells were consistently recovered. FACS analysis indicated that the majority $(>90 \%)$ of these cells were of human B lymphoid origin. A notable feature of the ascites cells was that expression of the adhesion molecules ICAM-1 and LFA-3 was markedly depressed relative to the parent LCL. Ascites cell cultures in vitro showed little evidence of the clumping that is characteristic of LCL; this was presumably a reflection of ICAM-1 and LFA-3 downregulation.

J. R. and D. P. LCL were newly established lines, and had been in culture for about 1 mo. In contrast, the third LCL (designated R. S.), transferred to SCID mice was a long term cell line, having been continuously passaged for almost a year since its inception. RS LCL $\left(3 \times 10^{6}\right)$ were transferred intraperitoneally to each of three mice. Remarkably, no disease was seen in these mice until day 70 posttransfer, whereupon the first mouse became ill and was sacrificed. Autopsy revealed tumor masses in the abdomen, liver, and thymus. Similar gross pathology was observed in the second and third mice (days 81-86). Flow cytometry confirmed that the tumor cells were human B lymphoid cells. Histopathologic analysis indicated that the tumors were large cell immunoblastic nonplasmacytoid lymphomas, with less differentiation than the tumors seen after EBV infection of SCID/hu chimeras (Fig. $1 B$ ).

\section{Discussion}

We describe a new model for EBV-induced aggressive fatal human lymphoproliferative disease in SCID mice reconsti- 
Table II. Transfer of EBV-transformed LCL to SCID Mice

\begin{tabular}{cccc}
\hline Cells transferred & $\begin{array}{c}\text { No. of } \\
\text { mice }\end{array}$ & $\begin{array}{c}\text { Time of } \\
\text { clinical disease }\end{array}$ & \multicolumn{1}{c}{ Gross pathology } \\
\hline $5 \times 10^{6}$ J.R. LCL & 3 & Days 19-21 & $\begin{array}{c}\text { No tumors } \\
\text { Ascites }(2 / 3) \\
1 / 3 \text { healthy up to day } 69\end{array}$ \\
$5 \times 10^{6}$ D.P. LCL & 3 & Days $14-17$ & $\begin{array}{c}\text { No tumors } \\
\text { Ascites }(2 / 3) \\
\text { one found dead day } 17\end{array}$ \\
$3 \times 10^{6}$ R.S. LCL & 3 & Days 70-86 & $\begin{array}{c}\text { Tumors in abdomen, } \\
\text { liver, thymus }(3 / 3)\end{array}$ \\
& & & No ascites* $(2 / 3)$
\end{tabular}

* A few cells $\left(4 \times 10^{6}\right)$ recovered $1 / 3$.

tuted with human leukocytes. Resultant tumors were of human B cell origin, and possessed EBV DNA sequences; histopathologically the tumors were large B cell immunoblastic lymphomas with prominent plasmacytoid differentiation and extensive well-defined areas of necrosis. These features are shared by human posttransplant lymphoproliferative disorders (16-18). Preliminary analysis of Ig light chain expression indicated that the SCID/hu tumors were oligoclonal or polyclonal; organ transplant associated lymphoproliferative disorders have been found to be monoclonal, multiclonal or polyclonal by analyses of cellular Ig expression (17), Ig gene rearrangements (18), or EBV terminal repeats (3). It has been suggested that monoclonal tumors may develop from a polyclonal hyperplastic background $(3,17)$.

Organ transplant-associated lymphoproliferative disorders develop in immunosuppressed individuals with impaired EBV-specific T cell immunity (1). The SCID/hu chimeras clearly lack EBV-specific $\mathrm{T}$ cell immunity as they are reconstituted with EBV seronegative cells. Although uncontrolled proliferation of EBV infected B cells would occur under these conditions, such proliferation alone would not produce the aggressive solid tumors characteristic of the posttransplant disorders in man and the EBV-injected SCID/hu chimeras described here. The additional factor(s) responsible for tumor development remain to be identified; neither the posttransplant disorders nor the SCID/hu tumors possess the c-myc or bcl-2 chromosomal translocations characteristic of Burkitt's lymphoma and human follicular lymphomas, respectively.

Although the tumors in the SCID/hu chimeras undoubtedly reflect EBV infection of $B$ cells in vivo, in vitro EBVtransformed short-term LCL produced ascites but not tumors. The explanation for the markedly different biological consequences of in vivo and in vitro EBV infection is not known. A long-term LCL line behaved differently, however, and produced tumors 70-86 d after transfer. Long-term LCL have previously been reported to be tumorigenic in $\mathrm{nu} / \mathrm{nu}$ mice (19).

In summary, we have developed a novel animal model for EBV-induced human lymphoproliferative disorders and lymphomas. The model most closely resembles the EBV-related lymphoproliferative disorders that represent a frequent complication in immunosuppressed individuals receiving organ transplants, but it may also be a model for certain other EBV- associated lymphomas in man. Since the roles of EBV, the target $\mathrm{B}$ cell, and $\mathrm{T}$ cell immunity can be independently and rapidly assessed in this model system, further studies will yield insights into the role of each in the development of human lymphoproliferative disorders.

\section{Acknowledgments}

The authors thank Dr. Oliver W. Jones of the Department of Genetics, University of California, San Diego, for performing the karyotypic analyses; Dr. Bruce Robbins of the Department of Pathology, Scripps Clinic and Research Foundation for histopathologic consultation; Bonnie Bradt for technical assistance and Bonnie Weier for preparation of the manuscript.

This work was supported by National Institutes of Health grants CA-14692, AI-25016, AR-33983, AI-17354, and HL-07195. Dr. Pisa is partly supported by the Swedish Medical Research Council and the Swedish Cancer Society. This is publication No. 6027-IMM from the Research Institute of Scripps Clinic.

\section{References}

1. Gaston, J. S. H., A. B. Rickinson, and M. A. Epstein. 1982. Epstein-Barr-virus-specific T-cell memory in renal allograft recipients under long-term immunosuppression. Lancet. i:923-925.

2. Hanto, D. W., G. Frizzera, K. Gajl-Peczalska, and R. L. Simmons. 1985. Epstein-Barr virus, immunodeficiency, and B cell lymphoproliferation. Transplantation. 39:461-472.

3. Cleary, M. L., M. A. Nalesnik, W. T. Shearer, and J. Sklar. 1988. Clonal analysis of transplant-associated lymphoproliferations based on the structure of the genomic termini of the Epstein-Barr virus. Blood. 72:349-352.

4. Pelicci, P.-G., D. M. Knowles II, Z. A. Arlin, R. Wieczorek, P. Luciw, D. Dina, C. Basilico, and R. Dalla-Favera. 1986. Multiple monoclonal $B$ cell expansions and c-myc oncogene rearrangements in acquired immune deficiency syndrome-related lymphoproliferative disorders. Implications for lymphomagenesis. J. Exp. Med. 164:20492060.

5. Hamilton-Dutoit, S. J., G. Pallesen, J. Karkov, P. Skinhoj, M. B. Franzmann, and C. Pedersen. 1989. Identification of EBV-DNA in tumour cells of AIDS-related lymphomas by in-situ hybridisation. Lancet. i:554-555.

6. Miller, G. 1979. Experimental carcinogenicity by the virus in vivo. In The Epstein-Barr Virus. M. A. Epstein and B. G. Achong, editors. Springer-Verlag, New York. 352-372.

7. Johnson, D. R., L. G. Wolfe, G. Levan, G. Klein, I. Ernberg, and P. Aman. 1983. Epstein-Barr virus (EBV)-induced lymphoproliferative disease in cotton-topped marmosets. Int. J. Cancer. 31:91-97.

8. Cleary, M. L., M. A. Epstein, S. Finerty, R. F. Dorfman, G. W. Bornkamm, J. K. Kirkwood, A. J. Morgan, and J. Sklar. 1985. Individual tumors of multifocal EB virus-induced malignant lymphomas in tamarins arise from different B-cell clones. Science (Wash. DC). 228:722-724.

9. Bosma, G. C., R. P. Custer, and M. J. Bosma. 1983. A severe combined immunodeficiency mutation in the mouse. Nature (Lond.). 301:527-530.

10. Mosier, D. E., R. J. Gulizia, S. M. Baird, and D. B. Wilson. 1988. Transfer of a functional human immune system to mice with severe combined immunodeficiency. Nature (Lond.). 335:256-259.

11. Boyce, S. T., and R. G. Ham. 1985. Cultivation, frozen storage, and clonal growth of normal human epidermal keratinocytes in serum-free media. J. Tissue Culture Methods. 9:83.

12. Rickinson, A. B., M. Rowe, I. J. Hart, Q. Y. Yao, L. E. Henderson, H. Rabin, and M. A. Epstein. 1984. T-cell-mediated regression of "spontaneous" and of Epstein-Barr virus-induced B-cell transformation in vitro: studies with cyclosporin A. Cell. Immunol. 87:646658. 
13. Fox, R. I., G. Pearson, and J. H. Vaughan. 1986. Detection of Epstein-Barr virus-associated antigens and DNA in salivary gland biopsies from patients with Sjogren's syndrome. J. Immunol. 137:3162-3168.

14. Dambaugh, T., C. Beisel, M. Hummel, W. King, S. Fennewald, A. Cheung, M. Heller, N. Raab-Traub, and E. Kieff. 1980. EpsteinBarr virus (B95-8) DNA VII: Molecular cloning and detailed mapping. Proc. Natl. Acad. Sci. USA. 77:2999-3003.

15. Gregory, C. D., R. J. Murray, C. F. Edwards and A. B. Rickinson. 1988. Downregulation of cell adhesion molecules LFA-3 and ICAM-1 in Epstein-Barr virus-positive Burkitt's lymphoma underlies tumor cell escape from virus-specific T cell surveillance. J. Exp. Med. 167:1811-1824.

16. Hanto, D. W., K. J. Gajl-Peczalska, G. Frizzera, D. C. Arthur, H. H. Balfour, Jr., K. McClain, R. L. Simons, and J. J. Najarian. 1983.
Epstein-Barr virus (EBV) induced polyclonal and monoclonal B-cell lymphoproliferative diseases occurring after renal transplantation. Ann. Surg. 198:356-369.

17. Cleary, M. L., R. Warnke, and J. Sklar. 1984. Monoclonality of lymphoproliferative lesions in cardiac-transplant recipients. Clonal analysis based on immunoglobulin-gene rearrangements. $N$. Engl. J. Med. 310:477-482.

18. Frizzera, G., D. W. Hanto, K. J. Gajl-Peczalska, J. Rosai, R. W. McKenna, R. K. Sibley, K. P. Holahan, and L. L. Lindquist. 1981. Polymorphic diffuse B-cell hyperplasias and lymphomas in renal transplant recipients. Cancer Res. 41:4262-4279.

19. Nilsson, K., B. C. Giovanella, J. S. Stehlin, and G. Klein. 1977. Tumorigenicity of human hematopoietic cell lines in athymic nude mice. Int. J. Cancer. 19:337-344. 